\title{
Thermo-ultrasound method for determining the damage of structural material
}

\author{
Alexander Gonchar ${ }^{1, *}$, Vasily Mishakin ${ }^{1}$, and Konstantin Kurashkin ${ }^{1}$ \\ ${ }^{1}$ Mechanical Engineering Research Institute of RAS - branch of the "Federal Research Center The \\ Institute of Applied Physics of the RAS", 85, Belinskogo str., Nizhny Novgorod, 603024, Russian \\ Federation.
}

\begin{abstract}
The effect of plastic strain and temperature on the longitudinal and shear waves velocity of austenitic stainless steel $12 \mathrm{Kh} 18 \mathrm{~N} 10 \mathrm{~T}$ (analogue AISI 321) is investigated. Cryogenic corrosion-resistant austenitic steel $12 \mathrm{Kh} 18 \mathrm{~N} 10 \mathrm{~T}$ is interesting due to the fact, that during plastic deformation a martensitic phase is formed. The martensitic phase significantly changes the electromagnetic, elastic and strength properties of the entire material. The formation of a new phase in conjunction with the process of plastic deformation has a significant effect on the temperature dependence of the elastic wave velocity. As a result of the studies, numerical values of the temperature-velocity factor for longitudinal and shear ultrasonic waves in steel $12 \mathrm{Kh} 18 \mathrm{~N} 10 \mathrm{~T}$ were obtained. The relationship between changes of the magnetic phase and temperaturevelocity factor is suggested; it can be used for determining the material damage by the ultrasound method.
\end{abstract}

\section{Introduction}

Operation of equipment in difficult climatic conditions of the Arctic and the Far North sets specific requirements for the diagnostics of the structural elements state using nondestructive testing methods. Investigation of the effect of negative temperatures on acoustic characteristics is necessary to improve the accuracy of determining the location and size of defects in ultrasound [1]. The damage of material, for example, under plastic deformation, can significantly affect the acoustic characteristics and the temperature dependence of elastic waves velocities, which leads to an increase in the error in the flaw detection of products [2].

It is known that during the operation of structures under mechanical loads, accumulation of microdamages in the form of micropores, microcracks, etc. takes place in the material. That leads to a change in the elastic and acoustic properties [3, 4]. The change in temperature also has a significant effect on the elastic modulus of metals and their alloys [5-8].

It is known that in steels of this class the $\alpha^{\prime}$ - martensite phase forms from the austenite phase thus reducing volume of the austenite phase under plastic deformation.

\footnotetext{
*Corresponding author: imndt31@mts-nn.ru
} 
The difference in the elastic modulus of martensite from the austenite modulus leads to a change in the elastic and acoustic characteristics of the entire material. The influence of structural changes occurring during plastic deformation and temperature on the elastic characteristics of the material is of great interest in scientific and applied terms.

To solve the problem of early diagnosis of the state of the material, the ultrasonic method is widely used. It is generally accepted that the temperature-velocity factor -the dependence of the elastic wave velocity on temperature for a particular material is a constant. In this paper, it is shown that the temperature-velocity factor for stainless steel $12 \mathrm{Kh} 18 \mathrm{~N} 10 \mathrm{~T}$ essentially depends on the plastic deformation.

The purpose of this work is to investigate the dependence of the ultrasonic waves velocity in structural steel $12 \mathrm{Kh} 18 \mathrm{~N} 10 \mathrm{~T}$ on the temperature at plastic deformation and to develop a method for determining the material damage.

\section{Experimental technique}

The material investigated was cryogenic austenitic stainless steel 12Kh18N10T (analogue of AISI 321). The chemical composition is (mass\%): C 0.02, Si 0.43, Mn 0.74, Cr 17.76, Ni 9.16, Ti 0.32, S 0.002, P 0.033, Cu 0.23.

Uniaxial tension was performed with a deformation rate of $\dot{\varepsilon}=10^{-4} \mathrm{~s}^{-1}$ at room temperature. The specimen for tensile test was $100 \mathrm{~mm}$ in gage length, $20 \mathrm{~mm}$ in gage width and $6 \mathrm{~mm}$ gage thickness.

The tests were carried out on an electromechanical universal tearing machine -Tinius Olsen H100KU. The stretching was carried out in stages, ultrasonic and eddy current studies were carried out before the tests and after each stage. The deformation was carried out prior to neck formation.

To measure the time of propagation of longitudinal and shear elastic waves, we used the echo-pulse method, utilizing broadband acoustic transducers V156-RM (shear wave) and V110-RM (longitudinal wave) made by Olympus. The central frequency of the piezoelectric transducers was about $5 \mathrm{MHz}$, their diameter was $6 \mathrm{~mm}$. Longitudinal and shear waves propagate along the $\mathrm{Z}$ axis (Fig. 1a). The error in measurement of the wave propagation time was 2-3 ns.
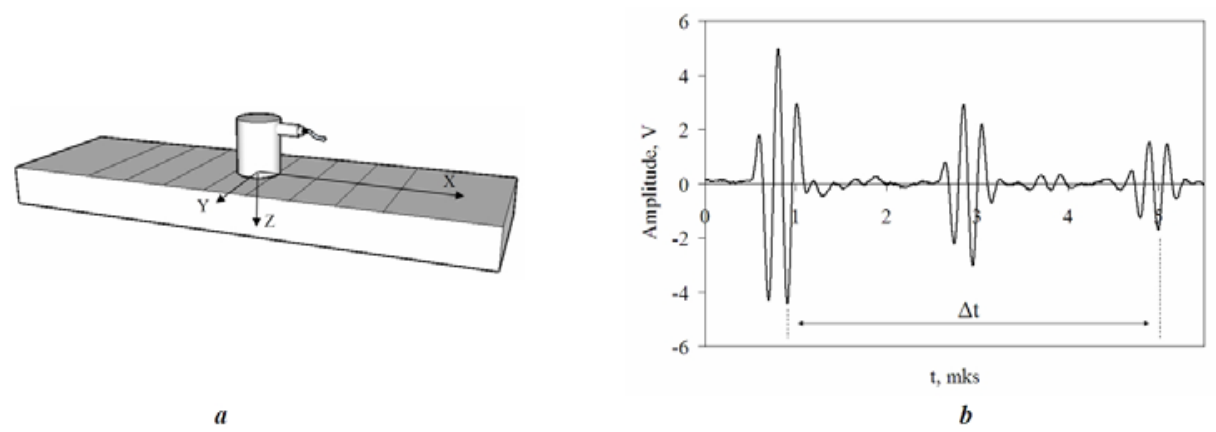

Fig. 1. a - schematic diagram of acoustic measurements; b - amplitude-time diagram of the ultrasonic impulse.

The sample with the sensor was placed in a cold chamber in which they were cooled at a rate of $10 \mathrm{~K} / \mathrm{h}$. During the process of cooling amplitude-time diagrams were recorded. The propagation time of ultrasonic pulses $\Delta \mathrm{t}$ on the amplitude-time diagram was determined between the first and third reflected pulses (Fig. 1b). The elastic waves velocity was calculated by the formula $V=4 h / \Delta t$, where $h=h_{0}(1-\alpha \Delta T), h_{0}$ is the thickness 
measured at $T_{0}=293 \mathrm{~K}\left(20^{\circ} \mathrm{C}\right), \alpha$ is the thermal linear expansion coefficient $\alpha=16.1 \times 10$ ${ }^{-6} K^{-1}, \Delta T=T_{0}-T, T$ - current measurement temperature.

The multifunctional eddy current instrument IMP-2M made was used to determine the volume fraction of the magnetic $\alpha^{\prime}$ - martensite phase $\Phi$ in materials. The relative error in determining $\Phi$ did not exceed $5 \%$.

\section{Results and discussion}

The temperature dependences of the longitudinal $V_{\mathrm{z}}$ and shear $V_{\mathrm{y}}$ elastic waves velocities in the temperature range $-55^{\circ} \mathrm{C}<\mathrm{T}<65^{\circ} \mathrm{C}$ are close to linear, Fig. 2 .

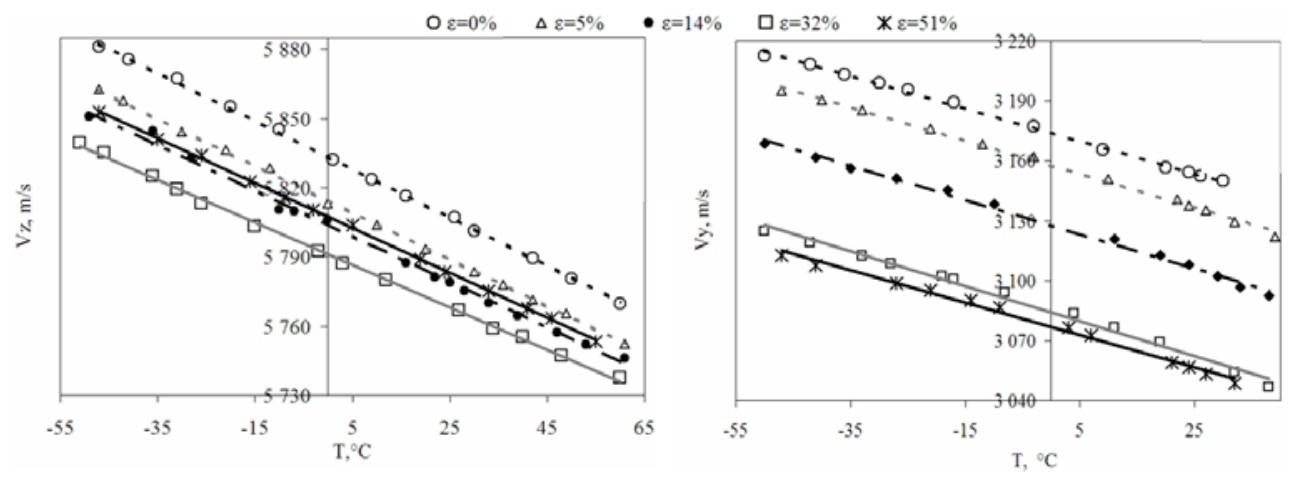

Fig. 2. Dependence of the ultrasonic wave velocity on the temperature for different plastic strain. (a longitudinal wave, $\mathrm{b}$ - shear wave).

The slopes and the free term of the curves depend on the plastic strain. The dependence of the ultrasonic velocity on the temperature can be represented as:

$$
V_{z, y}(\varepsilon)=k_{z, y}(\varepsilon) T+b_{z, y}(\varepsilon)
$$

where $k_{z, y}$ is the temperature-velocity factor of the longitudinal and shear waves, respectively, $k_{z, y}=\left(V_{z, y}-V_{z, v}^{0}\right) /\left(T-T_{0}\right)$, where $V_{z, y}$ is the longitudinal and shear waves velocity at temperature $T$, respectively; $V_{z}^{0}{ }_{, v}$ is the longitudinal and shear waves velocity at temperature $T_{0}$, respectively, and $b_{z, v}$ is the free term, determines the velocity at $T=0{ }^{\circ} \mathrm{C}$. With plastic deformation up to $\varepsilon=32 \%$, the longitudinal wave velocity decreases monotonically, Fig. 3a. The change in the longitudinal wave velocity at room temperature of the $20^{\circ} \mathrm{C}$ was $0.7 \%$. At a plastic strain $\varepsilon=51 \%$, the longitudinal waves velocity increased slightly. This can be explained by an intensive texture changes in the late stages of deformation. The relationship between the longitudinal wave velocity $V_{z}$ and deformation $\varepsilon$, with deformation up to $\varepsilon=32 \%$, can be described by the second-degree polynomial:

$$
V_{z}=k_{1} \varepsilon^{2}+k_{2} \varepsilon+k_{3}
$$

where $k_{1}=0.04 \mathrm{~m} / \mathrm{s}, k_{2}=-2.45 \mathrm{~m} / \mathrm{s}, k_{3}=5810 \mathrm{~m} / \mathrm{s}$.

With plastic deformation up to $\varepsilon=32 \%$, the shear wave velocity decreases linearly, Fig. 3b. With plastic strain $\varepsilon=32 \%$, the speed decreased by $3.7 \%$. At a plastic strain $\varepsilon=$ $52 \%$, the rate decreased to $4.6 \%$ relative to the initial value. Thus, it can be concluded that the shear waves polarized across the extension axis are more sensitive to deformations than 
the longitudinal ones. The relationship between the shear wave velocity $V_{\mathrm{y}}$ and plastic strain, with deformation up to $\varepsilon=32 \%$, is approximately: polynomial:

$$
V_{y}=k_{4} \varepsilon+k_{5}
$$

where $k_{4}=-3.64 \mathrm{~m} / \mathrm{s}, k_{5}=3170 \mathrm{~m} / \mathrm{s}$.

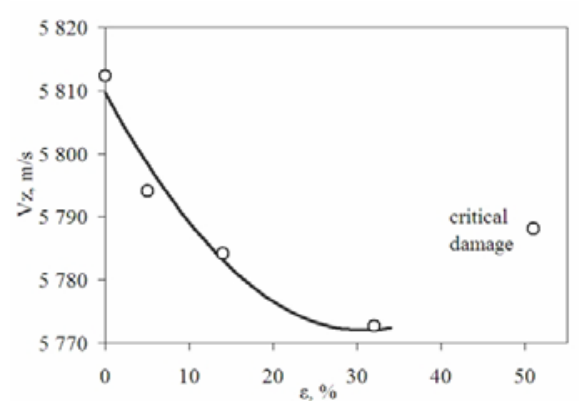

a

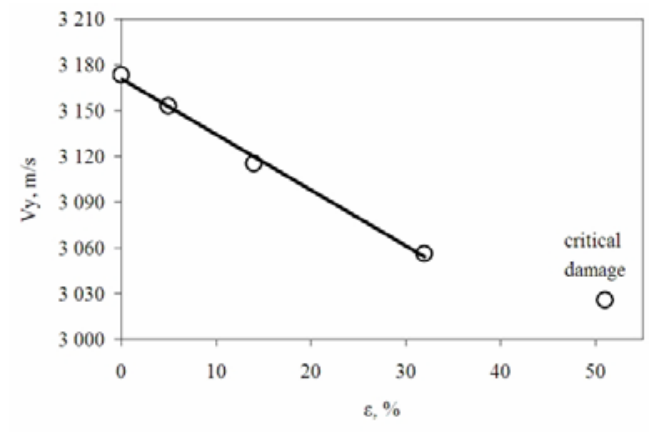

$\mathrm{b}$

Fig. 3. Dependence of the ultrasonic wave velocity at $20{ }^{\circ} \mathrm{C}$ on the plastic strain (a- longitudinal wave; $b$ - shear wave).

The temperature-velocity factors of longitudinal $K_{z}$ and shear $K_{\mathrm{y}}$ wave is a structurally sensitive characteristic of the material. It is reflecting changes in the microstructure during plastic deformation, Fig. 4.
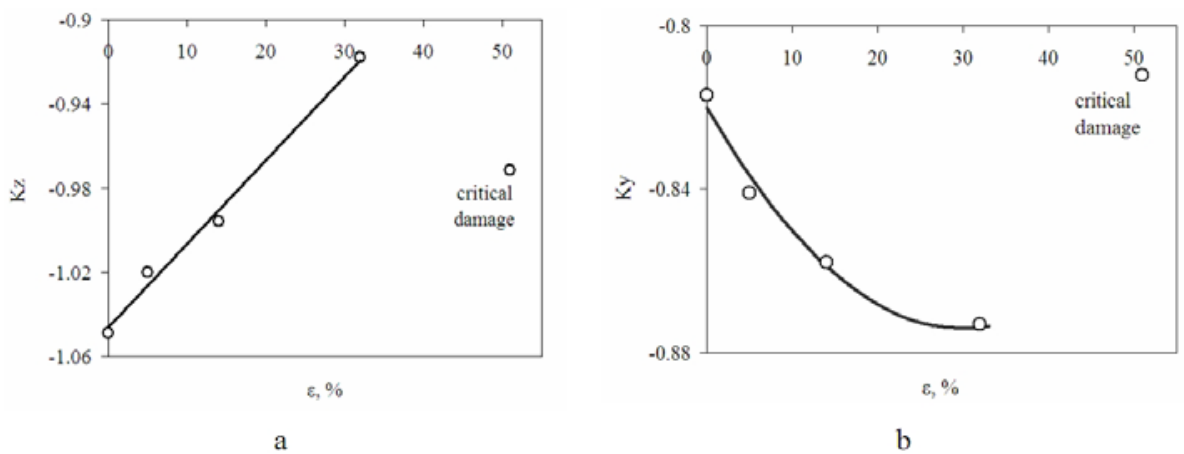

Fig. 4. Dependence of the temperature-velocity factors on the plastic strain (a - longitudinal wave; b shear wave).

The temperature-velocity factors of longitudinal waves decreases by an absolute value by $12 \%$, for shear waves increases by $7 \%$ during the deformation. The relationship between the temperature-velocity factors and plastic strain for longitudinal waves is linear, while for shear waves it is quadratic:

$$
\begin{gathered}
k_{z}=k_{6} \varepsilon+k_{7} \\
k_{y}=k_{8} \varepsilon^{2}+k_{9} \varepsilon+k_{10}
\end{gathered}
$$

where $k_{6}=4 \times 10^{-3} \mathrm{~m} /(\mathrm{s} \times \mathrm{K}), k_{7}=-1.05 \mathrm{~m} /(\mathrm{s} \times \mathrm{K}), k_{8}=6 \times 10^{-5} \mathrm{~m} /(\mathrm{s} \times \mathrm{K}), k_{9}=-3.6 \times 10^{-3} \mathrm{~m} /(\mathrm{s} \times \mathrm{K})$, $k_{10}=-0.82 \mathrm{~m} /(\mathrm{s} \times \mathrm{K})$. 
It is known that a new phase of $\alpha$ '- martensite is formed under plastic deformation metastable austenitic steel $[9,10]$. The volume of the $\alpha$ '- martensite phase increases during plastic deformation, Fig. 5.

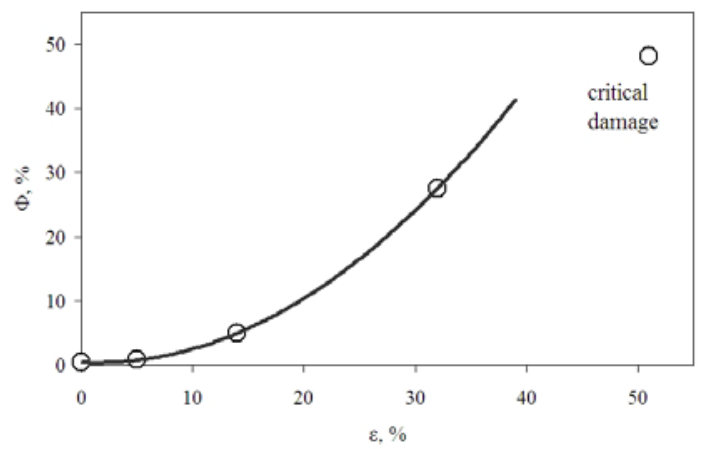

Fig. 5. Dependence of the volume percent martensite on the plastic strain.

The evolution of the microstructure in the form of the growth of a new phase significantly changes the strength characteristics of the material. Precipitation of hard strengthening martensite particles leads to an increase in the strain in the microvolumes of a soft phase (austenite) and to a sharp increase in the energy density of plastic deformation, which causes rapid formation of microdefects [11].

In this sense, the amount of $\alpha$-martensite phase formed can be considered the degree of degradation. Thus, the material damage $\psi$ can be represented as a relative change in the martensite phase:

$$
\psi=\Phi / \Phi^{*}
$$

where $\Phi$ - the current value of the precipitated phase of martensite, $\Phi^{*}-$ the critical value of the martensite phase at which the material is destroyed $\left(\Phi^{*}=50 \%\right)$. The obtained relations between the damage and the temperature-velocity factor of longitudinal $K_{z}$ and shear $K_{\mathrm{y}}$ waves (Fig. 6) can be represented as follows:

$$
\begin{gathered}
\psi=k_{11} k_{z}^{2}+k_{12} k_{z}+k_{13} \\
\psi=k_{14} e^{k_{15} k_{y}}
\end{gathered}
$$

where $k_{11}=33.9 \quad((\mathrm{~s} \times \mathrm{K}) / \mathrm{m})^{2}, \quad k_{12}=71 \quad(\mathrm{~s} \times \mathrm{K}) / \mathrm{m}, \quad k_{13}=37.15, \quad k_{14}=1.16 \times 10^{-30}, \quad k_{15}=-77.9$ $(\mathrm{s} \times \mathrm{K}) / \mathrm{m}$.
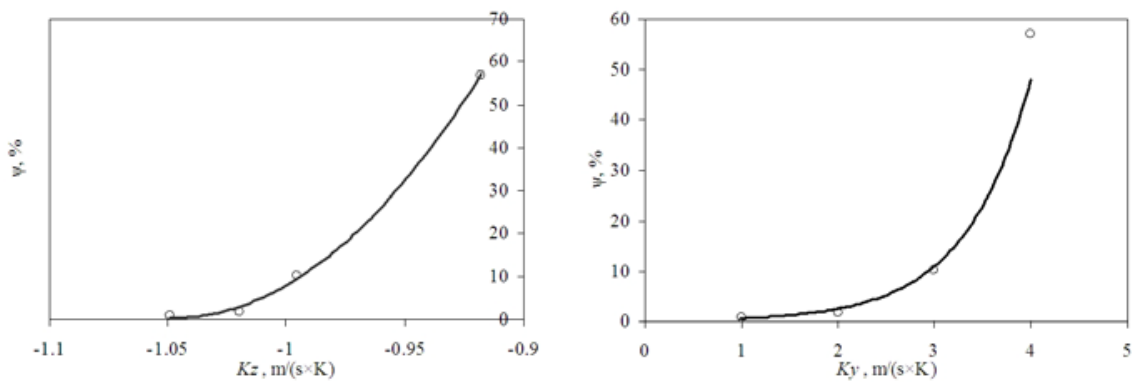

Fig. 6. Relation between the damage and temperature-velocity factor ( $\mathrm{a}$ - longitudinal waves; $\mathrm{b}$ shear waves). 
Thus, by means of ultrasonic measurements, the material's damage can be determined by changing the temperature of the material.

\section{Conclusion}

Ultrasonic studies of the effect of temperature in the range from $-50^{\circ} \mathrm{C}$ to $+40^{\circ} \mathrm{C}$ and plastic strain on the velocities of longitudinal and shear elastic waves have shown that the volume fraction of the $\alpha^{\prime}$-martensite phase is related to the temperature-velocity factor.

It is found that the temperature-velocity factor for longitudinal waves decreases by an absolute value by $12 \%$, for shear waves by $7 \%$ under plastic deformation.

An ultrasonic method for determining the damage under plastic deformation of austenitic steel $12 \mathrm{Kh} 18 \mathrm{~N} 10 \mathrm{~T}$ is proposed based on the measurement of the temperaturevelocity factor of longitudinal and shear elastic waves.

This work was supported by grant of the President of the Russian Federation (MK-6069.2018.8).

\section{References}

1. A.A. Deryabin, N.P. Aleshin, Conference "Materials for technical devices and structures used in the Arctic", Moscow, November, (2015).

2. A.V. Gonchar, V.V. Mishakin, V.A. Klyushnikov, K.V. Kurashkin, S.A. Sorokina, Influence of negative temperatures and damage on the acoustic characteristics of AMg6 alloy, Defectoscopy, v. 4, pp. 66-70 (2017).

3. Lemaitre, Theoretical foundations of engineering calculations, v. 107, p. 124 (1985).

4. R.L. Salganik. Mechanics of a solid body, v. 4, p. 149 (1973).

5. A.S. Wagh, R.B. Poeppel, J.P. Singh. J. Mater.Sci., v. 26, p. 3862 (1991).

6. R.G. Munro, Journal of Research of NIST, v 109(5), pp. 497-503 (2004).

7. J.F. Bell. Experimental Foundations of Mechanics of Deformable Solids. Science, p. 1027 (1984).

8. Y.P. Varshni. Phys. Rev. B, v. 2, p. 3952 (1970).

9. A.V. Gonchar, O.N. Bizyaeva, V.A. Klyushnikov and V.V. Mishakin, Ultrasonic and Eddy-Current Study of Plastic Deformation Austenitic-Steel Welds, Russian Journal of Nondestructive Testing, v. 52(10), pp. 610-616 (2016).

10. B.A. Behrens, S. Hübner, A. Bouguecha, J. Knigge, K. Voges-Schwieger, K. Weilandt, Local Strain Hardening of Metal Components by Means of Martensite Generation, Advanced Materials Research, v. 137, p. 1-33 (2010).

11. V. V. Mishakin, V. A. Klyushnikov, and A. V. Gonchar, Relation between the Deformation Energy and the Poisson Ratio during Cyclic Loading of Austenitic Steel, Technical Physics, v. 60(5), pp. 665-668 (2015). 